\title{
An introduction to CKD-MBD research: restart for the future
}

\author{
Masafumi Fukagawa $^{1}$ Masaaki Inaba ${ }^{2} \cdot$ Keitaro Yokoyama $^{3}$ 'Takashi Shigematsu ${ }^{4}$. \\ Ryoichi Ando $^{5} \cdot$ Ken-ichi Miyamoto ${ }^{6}$ For Japan CKD-MBD Forum
}

Published online: 12 January 2017

(C) Japanese Society of Nephrology 2017

The kidney plays important roles in the regulation of mineral metabolism. It is not only the target organ of mineral regulating hormones, but also the main organ that activates vitamin D [1]. Accordingly, in CKD patients, various abnormalities develop in this system, such as secondary hyperparathyroidism [2,3]. As partially depicted in this issue, Japanese researchers have substantially contributed to the elucidation of pathogenesis of these abnormalities, leading to the development of new therapeutic modalities [4-6].

Abnormal mineral metabolism in CKD has recently been renamed from renal osteodystrophy (ROD) to chronic kidney disease-mineral and bone disorder (CKDMBD) as a syndrome [7]. Since CKD-MBD is a systemic

The Council members of "Japan CKD-MBD Forum" are listed in Acknowledgements.

Masafumi Fukagawa

fukagawa@tokai-u.jp

1 Division of Nephrology, Endocrinology and Metabolism, Tokai University School of Medicine, 143 Shimo-Kasuya, Isehara, Kanagawa 259-1193, Japan

2 Department of Metabolism, Endocrinology and Molecular Medicine, Osaka City University Graduate School of Medicine, Osaka, Japan

3 Division of Nephrology and Hypertension, Department of Internal Medicine, The Jikei University School of Medicine, Tokyo, Japan

4 Department of Nephrology and Blood Purification Medicine, Wakayama Medical University, Wakayama, Japan

5 Musashino Red Cross Hospital, Tokyo, Japan

6 Department of Molecular Nutrition, Institute of Biomedical Sciences, Tokushima University Graduate School, Tokushima, Japan disorder, we treat or prevent these abnormalities to decrease the risk of hard outcomes, such as cardiovascular disease, bone fracture and mortality. Among them, cardiovascular risk [8] has been mainly attributed to vascular calcification, however, thanks to the recent discoveries on the new roles of FGF23 [9, 10], CKD-MBD has expanded its concept, to further including left ventricular hypertrophy, heart failure, immune dysfunction, inflammation, anemia and iron deficiency. As for the bone abnormalities, recent reports suggest that abnormal bone quality also play important roles in bone fragility in CKD patients [11].

Care of CKD patients, especially for dialysis patients, has been traditionally quite intensive in Japan, which could have potentially contributed to the much better prognosis than other countries [12]. Achievement of strict target range of mineral parameters by Japanese guidelines $[13,14]$, especially focused on phosphorus $[15,16]$, may in part explain such a better prognosis [17]. In addition, because the number of kidney transplant recipients in Japan has been slowly growing, pre and post-transplant of CKDMBD is also becoming another important topic in research and management [18].

There have been two active research meetings specialized on CKD-MBD research in Japan, i.e., The Research Meeting on Kidney and Metabolic Bone Disease (1983-2016) and The Japanese Society for Kidney Bone Disease (JSKBD) (1990-2016). To develop more intensive discussions among clinicians and researchers, these meetings have merged, and will restart from 2017 as Japan CKD-MBD Forum (Fig. 1).

On behalf of founding members, we hope discussions at this new 'Japan CKD-MBD Forum' will contribute to the elucidation of new pathogenetic mechanisms and to the 


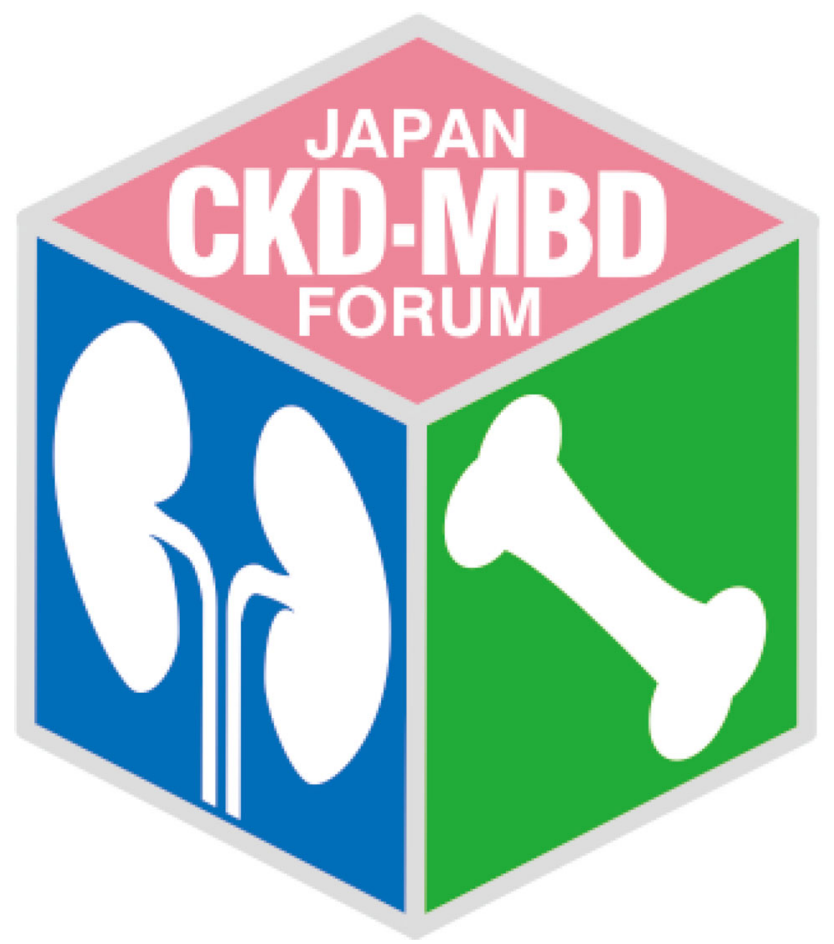

Fig. 1 Logo of the new research meeting for CKD-MBD in Japan (Copyright owned by Japan CKD-MBD Forum, with permission)

development of globally relevant evidences, which contribute to future guidelines $[19,20]$.

Guest Editor

Masafumi Fukagawa, MD, PhD

Acknowledgements This supplement is supported by grants from The Japanese Society for Kidney Bone Disease (JSKBD) and from The Research Meeting on Kidney and Metabolic Bone Disease. We are grateful to the members of these two societies for their assistance, especially to Takashi Akiba MD, PhD, and Eriko Kinugasa, MD, PhD.

List of contributors Council members of Japan CKD-MBD ForumMasafumi Fukagawa, MD, PhD, Masaaki Inaba, MD, PhD, Keitaro Yokoyama, MD, PhD, Takashi Shigamatsu, MD, PhD, Ryoichi Ando, MD, PhD, Ken-ichi Miyamoto PhD.

\section{Compliance with ethical standards}

Conflict of interest MF has received honoraria, consulting fee, and grant/research support from Kyowa Hakko Kirin, Bayer Yakuhin, and Torii Pharmaceutical. MI has received honoraria from Bayer Yakuhin, Kyowa Hakko Kirin, Daiichi-Sankyo, MSD, Takeda pharmaceutical, Chugai Pharmaceutical, Astellas, Nihon Lilly, Asahi Kasei and Ono Pharmaceutical, and grant from Nihon Lilly. KY has received honoraria from Kyowa Hakko Kirin and Torii Pharmaceutical. TS has received research grants from Torii Pharmaceutical, and lecturer fees from Chugai Pharmaceutical, Kyowa Hakko Kirin, Astellas Co, Bayer Yakuhin, and Kissei Pharmaceutical, and consulting fees from Kyowa Hakko Kirin and Ono Pharmaceutical. RA has received honoraria from Chugai Pharmaceutical, kyowa Hakko Kirin and Torii Pharmaceutical. K-I M declared no conflict of interest.

\section{References}

1. Fukagawa M, Hamada Y, Nakanishi S, Tanaka M. The kidney and bone metabolism: a nephrologist's view. J Bone Mineral Metab. 2006;24:434-8.

2. Komaba H, Kakuta T, Fukagawa M. Diseases of the parathyroid gland in chronic kidney disease. Clin Exp Nephrol. 2011;5:797-809.

3. Komaba H, Kakuta T, Fukagawa M. Management of secondary hyperparathyroidism: how and why? Clin Exp Nephrol. 2017. doi:10.1007/s10157-016-1369-2.

4. Mizobuchi M, Ogata H, Koiwa F, Kinugasa E, Akizawa T. Research on kidney and mineral metabolism in Japan: Past, present and future. Clin Exp Nephrol. 2017. doi:10.1007/s10157016-1366-5.

5. Hamano T, Sakaguchi Y, Fujii N, Isaka Y. Clinical features of CKD-MBD in Japan: Cohort studies and registry. Clin Exp Nephrol. 2017. doi:10.1007/s10157-016-1367-4.

6. Miyamoto K-I, Kaneko I, Tatsumi S, Segawa H: Control of phosphate balance by the kidney and intestine. Clin Exp Nephrol. 2017. doi:10.1007/s10157-016-1359-4.

7. Moe S, Drueke T, Cunningham J, et al. Definition, evaluation, and classification of renal osteodystrophy: a position statement from kidney disease improving global outcomes (KDIGO). Kidney Int. 2006;69:1945-53.

8. Fuji H, Joki N. Mineral metabolism and cardiovascular disease in CKD. Clin Exp Nephrol. 2017. doi:10.1007/s10157-016-1363-8.

9. Komaba H, Fukagawa M. The role of FGF23 in CKD: with or without Klotho. Nature Review Nephrol. 2012;8:484-90.

10. Kuro-o M. The FGF23 and Klotho system beyond mineral metabolism. Clin Exp Nephrol. 2017. doi:10.1007/s10157-0161357-6.

11. Kazama JJ. Chronic kidney disease and fragilty fracture. Clin Exp Nephrol. 2017. doi:10.1007/s10157-016-1368-3.

12. Goodkin DA, Bragg-Gresham JL, Koenig KC, Wolfe RA, Akiba T, Andreucci VE, Saito A, Rayner HC, Kurokawa K, Port FK, Held PJ, Young EW. Association of comorbid conditions and mortality in hemodialysis patients in Europe, Japan, and the United States. Dialysis Outcome Practice Patterns Study (DOPPS). 2003;14:3270-7.

13. Fukagawa M, Yokoyama K, Koiwa F, Taniguchi M, Shoji T, Kazama JJ, Komaba H, Ando R, Kakuta T, Fujii H, Nakayama M, Shibagaki Y, Fukumoto S, Fujii N, Hattori M, Ashida A, Iseki K, Shigematsu T, Tsubakihara Y, Tomo T, Hirakata H. Akizawa $\mathrm{T}$ for CKD-MBD Guideline Working Group, Japanese Society for Dialysis Therapy: clinical Practice Guideline for the Management of Chronic Kidney Disease-Mineral and Bone Disorder (CKD-MBD). Ther Aphr Dial. 2013;17:247-88.

14. Taniguchi M, Fukagawa M, Fujii N, Hamano $T$, Shoji $T$, Yokoyama K, Nakai S, Shigematsu T, Iseki K, Tsubakihara Y. Committee of Renal Data Registry of the Japanese Society for Dialysis Therapy: impact of mineral metabolism on mortality in hemodialysis patients: Serum phosphate level should be controlled firstly and consistently. Ther Aphr Dial. 2013;17:221-8.

15. Komaba H, Fukagawa M. Phosphate- a poison for humans? Kidney Int. 2016;90:753-63.

16. Taketani T, Koiwa F, Yokoyama K. Management of phosphorus load in CKD patients. Clin Exp Nephrol. 2017. doi:10.1007/s10157016-1360-y.

17. Tentori F, Wang M, Bieber B, Jacobson S, Andreucci V, Fukagawa M, Frimat L, Mendelssohn DA, Port F, Pisoni RL, Robinson BM. Secondary hyperparathyroidism among patients on chronic hemodialysis: recent changes in therapeutic approach and association with outcomes in the dialysis outcomes and practice pattern study (DOPPS). Clin J Am Soc Nephrol. 2015;10:98-109. 
18. Hirukawa T, Kakuta T, Nakamura M, Fukagawa M. Mineral and bone disorders in kidney transplant recipients: reversible, irreversible and de novo abnormalities. Clin Exp Nephrol. 2015;19:543-55.

19. Kidney Disease: Improving Global Outcomes (KDIGO) CKDMBD Work Group: KDIGO clinical practice guideline for the diagnosis, evaluation, prevention and treatment of Chronic Kidney Disease-Mineral and Bone Disorder (CKD-MBD). Kidney Int 2009;76(Supple 113):S1-S130.
20. Ketteler M, Elder GJ, Evenepoel P, Ix JH, Jamal SA, LafageProust MH, Shroff R, Thadhani RI, Tonelli MA, Kasiske BL, Wheeler DC, Leonard MB. Revisiting KDIGO clinical practice guideline on chronic kidney disease-mineral and bone disorder: a commentary from a Kidney Disease: improving global outcomes controversies conference. Kidney Int. 2015;87:502-28. 